\title{
Is gastroesophageal reflux disease influenced by duodenogastric reflux
}

\author{
Mihaela-Aura Mocanu $^{1 *}$, Diculescu $\mathrm{M}^{1}$, Nicolae $\mathrm{T}^{1}$ and Mona Dumitrescu ${ }^{2}$ \\ ${ }^{1}$ Gastroenterology, Endoscopy and Hepatology Elias Clinic, Bucharest, Romania \\ ${ }^{2}$ Department of Statistics, University of Bucharest, Romania
}

\begin{abstract}
It is well known that the gastroesophageal reflux is a frequent disease in medical practice. A lot of factors are involved in its pathogenesis. The aim of our study was to find out if the duodenogastric reflux is one of these factors. We also looked for the pathological conditions associated with duodenogastric reflux. We studied a lot of 59c (30c females and 29c males) with ages between 39 and 54 years old suffering from gastroesophageal disease.

Material and methods: EDS examination and abdominal ultrasound were done and we calculated the score of gastroesophageal reflux by GERD Q method.

Results and discussion: Our results show the high frequency of cholesterolosis (45.7\%). All of these cases presented duodenogastric reflux, which means that biliary disease can be one of the causes of the gastroesophageal reflux.

Conclusion: The duodenogastric reflux aggravated gastroesophageal reflux and induced esophagitis in $50 \%$ of cases.
\end{abstract}

Our interest for gastroesophageal reflux is due to the high frequency of this disease. The well-known causes of GER disease are: impaired esophageal clearance, the altered antireflux mechanism and the diminished gastric motility. The antireflux mechanism include: the pressure of low esophageal sphincter, Hiss's angle and the abdominal part of esophagus. There are some date which describe also a duodenogastric reflux associated with gastric ulcer, esophagitis and gallbladder lithiasis $[1,2]$.

We wanted to know how frequent the duodenogastric reflux in patients with GERD is. We also tried to find which are associated disease with the duodenogastric reflux and if the duodenogastric reflux can aggravate GERD.

\section{Material and methods}

We analyzed 59c with GERD 30 females and 29 males aged between 39 and 54 years old. The diagnosis of GERD was done using clinical data and upper endoscopy Cal examination. The gastroduodenoscopy show if the bile is inside the stomach (that proved duodenogastric reflux) as well as the presence of esophagitis. At the same time by endoscopy we can exclude gastric and duodenal ulcers, gastric neoplasm, gastritis etc.

By abdominal ultrasound examination we looked for gallbladder diseases and we evaluated the gallbladder motility. We calculated the ejection ratio using the formula $\mathrm{EF}=\mathrm{V} 1-\mathrm{V} 2 / \mathrm{V} 1 \mathrm{x} 100 \mathrm{~V} 1=$ the fasting gallbladder volume, $\mathrm{V} 2=$ the volume after the ingestion of Boyden meal. Normal values are $50-60 \%$. The formula for gallbladder volumes is: $\mathrm{V}=0.5 \mathrm{xLx} \mathrm{lx} \mathrm{g}$ where $\mathrm{L}$ is the gallbladder length, $\mathrm{l}=$ the width of gallbladder and $g=$ the thickness of gallbladder wall [3].

By abdominal ultrasound examination we noticed all cases with enhanced duodenal motility. We calculated the GERDQ score in order to appreciate the severity of gastroesophageal reflux. We used the Astra Zeneca questionnaire in this study as well as in $\mathrm{PhD}$ thesis [4-7].
It contains 6 questions: 4 questions about symptoms and 2 questions about the impact of symptoms on the patient's life. The responses are filled in by the patient and then evaluated by the doctor. The questionnaire contains four tables: A, B, C, D. The last table D allows us to appreciate the severity of GERD.

(Table 1)

We use the total score and the impact score in order to calculate GERDQ score wich offers us information about othe severity of gastroesophageal reflux disease.

\section{Results}

We found duodenogastric reflux in $34 \%$ of our cases with GERD (Table 2). In 66\%(32c) we didn't find duodenogastric reflux.

Table 1. The GERDQ score and the severity of GERD

\begin{tabular}{|l|l|l|}
\hline Total score & The impact score & \\
\hline $0-2$ & - & The probability of GERD is low \\
\hline $3-7$ & - & The probability of GERD is low \\
\hline $8-10$ & $<3$ & GERD + with discomfort \\
& $>=3$ & GERD + disturbing symptoms \\
\hline $11-18$ & $<3$ & GERD with discomfort \\
& $>=3$ & GERD with disturbing symptoms \\
\hline
\end{tabular}

Correspondence to: Mihaela-Aura Mocanu, Gastroenterology, Endoscopy and Hepatology Elias Clinic, Bucharest, Romania, Tel: 011-40-241-722763629, E-mail: mmocanu2005@gmail.com

Key words: gastroesophageal reflux, duodenogastric reflux

Received: July 28, 2015; Accepted: September 18, 2015; Published: September 22, 2015 
Table 2. The incidence of duodenogastric reflux.

\begin{tabular}{|l|l|}
\hline The total nr. of cases & The nr. of cases with and without duodenogastric reflux (dgr) \\
\hline 59c & $\begin{array}{l}\mathbf{2 7} \text { cases with d.g.r. }=\mathbf{3 4 \%} \\
\mathbf{3 2} \text { cases without d.g.r. }=\mathbf{6 6} \%\end{array}$ \\
\hline
\end{tabular}

Table 3. The incidence of gallbladder cholesterolosis and the gallbladder motility.

\begin{tabular}{|l|l|l|}
\hline $\begin{array}{l}\text { Total nr. of } \\
\text { cases }\end{array}$ & $\begin{array}{l}\text { Nr. of cases with and without } \\
\text { gallbladder cholesterolosis }\end{array}$ & $\begin{array}{l}\text { The gallbladder motility evaluated by } \\
\text { E.R normal values } 50-60 \%\end{array}$ \\
\hline $\mathbf{5 9 c}$ & $\mathbf{+ 2 7 c ( \mathbf { 4 5 . 7 } \% )}$ & $\mathbf{2 5 c} \mathbf{E} . \mathbf{R}>\mathbf{5 0 - 6 0} \%=$ hyperkinesia \\
& $\mathbf{- 3 2 c ( 5 4 , 3 \% )}$ & $\mathbf{2 c} \mathbf{E R}=\mathbf{5 0 - 6 0} \%=$ normal motility \\
& & $\mathbf{3 2 c}=$ normal motility \\
\hline
\end{tabular}

The majority of cases with cholesterolosis have enhanced motility=hyperkinesias

Table 4. The incidence of duodenogastric reflux and esophagitis.

\begin{tabular}{|c|c|c|}
\hline Total nr. of cases & $\begin{array}{c}\text { Nr. of cases with and without } \\
\text { duodenogastric reflux }\end{array}$ & $\begin{array}{c}\text { Nr. of cases with } \\
\text { esophagitis }\end{array}$ \\
\hline $\mathbf{5 9 c}$ & $\mathbf{+ 2 0 c}$ & $+\mathbf{1 0 c}$ \\
& $\mathbf{- 3 9 c}$ & $\mathbf{- 3 9 c}$ \\
\hline
\end{tabular}

Table 5. The gallbladder cholesterolosis is associated with hyperkinesia, enhanced duodenal motility and duodenogastric reflux.

\begin{tabular}{|c|c|c|c|c|}
\hline $\begin{array}{l}\text { Total nr. of } \\
\text { cases }\end{array}$ & $\begin{array}{l}\text { Nr. of cases with } \\
\text { and without } \\
\text { duodenogastric reflux }\end{array}$ & $\begin{array}{l}\text { Nr. of cases with } \\
\text { without gallbladder } \\
\text { cholesterolosis }\end{array}$ & $\begin{array}{l}\text { Enhanced } \\
\text { duodenal } \\
\text { motility }\end{array}$ & $\begin{array}{l}\text { Gallbladder } \\
\text { motility E.R }>50 \text { - } \\
60 \%=\text { hyperkinesia }\end{array}$ \\
\hline $59 \mathrm{c}$ & $\begin{array}{l}+20 c \\
-39 c\end{array}$ & $\begin{array}{l}+27 c \\
-32 c\end{array}$ & $\begin{array}{l}+25 c \\
-34 c\end{array}$ & $\begin{array}{l}\text { 25c hyperkinesia } \\
\text { 34c normal } \\
\text { motility }\end{array}$ \\
\hline
\end{tabular}

Table 6. The duodenogastric reflux is correlated with enhanced duodenal motility, higher GERDQ score and esophagitis.

\begin{tabular}{|l|l|l|l|l|}
\hline $\begin{array}{l}\text { Total nr. } \\
\text { of cases }\end{array}$ & $\begin{array}{l}\text { The nr. of cases } \\
\text { with and without } \\
\text { duodenogastric reflux }\end{array}$ & $\begin{array}{l}\text { Enhanced } \\
\text { duodenal } \\
\text { motility }\end{array}$ & $\begin{array}{l}\text { GERDQ } \\
\text { score }\end{array}$ & Nr of cases with esophagitis \\
\hline 59c & $+\mathbf{2 0 c}$ & $\mathbf{+ 2 0 c}$ & $\mathbf{1 1 - 1 8}$ & $\begin{array}{l}\text { 10c œsophagites grade A LA } \\
\mathbf{1 0 c} \text { œsophagites grade B la 0 } \\
\text { 0c }\end{array}$ \\
\hline
\end{tabular}

Only in two cases $3.7 \%$ the gallblader has normal motility, 32 case without gallbladder cholesterolosis have normal gallblader motility (Table 3).

The duodenogastric reflux was found in 20 cases. From these cases 10 cases have esophagitis $50 \%$. In 39 cases without duodenogastric reflux we did not find any cases of esophagitis (Table 4).

We noticed that all cases with gallbladder cholesterolosis associate enhanced duodenal motility 25 cases from 27 (92\%) Enhanced duodenal motility is the "vehicle" for duodenal content which reach the stomach as a duodenogastric reflux.

We also observe that the cases with hyperkinetic gallblader have enhanced duodenal motility (Table 5).

We can notice that all cases with duodenalgastric reflux have enhanced duodenal reflux, high score GERDQ (11-18) and associate reflux esofagite: 10 cases with gade $\mathrm{A}$ and 10case with grade $\mathrm{B}$ esofagitis according to LA classification These data prove the role of duodenogastric reflux in pathogenesis of gastroesophageal reflux and its consecquences (Table 6).

\section{Discussion}

The duodenogastric reflux was described in about $25 \%$ cases of patients with GERD according to the paper of Brillantino and Monaco [1]. They described duodenogastric reflux associated with gastric ulcer, gallbladder lithiasis and esophagitis and they pointed that the duodenogastric reflux can damage the gastric and esophageal mucosa due to the fact that it contains biliary acids and pancreatic juice. It is not clear if the duodenogastric reflux can sometimes be found with normal people as a physiological event or is a pathological dismotily associated with gastroesophageal reflux. The duodenogastric reflux differs from transpiloric flow in the fact that it operates the bile and pancreatic juice inside the stomach and it happens in the interdigestive phase. Johnson a $\mathrm{G}$ noticed that none of these waves of transpiloric retrograde flow is due to antiperistalsis waves from $\mathrm{D} 2$.

In experimental study done on volunteers by intubation technique Keane, Dimango and Malagelada [2] have been measured the antral and duodenal pressure, the ph, the levels of bicarbonate, biliary acids and trypsin in gastric and duodenal juice. The Poly ethylene Glycol (PEG) was used as a marker which indicates the direction of fluid movement. All there data were recorded simultaneously with the phases of Interdigestive Motor Complexes (IMC). The authors found that the duodenogastric reflux has two components: the secretory phases which occur before phase III of IMC and the motor phase which occurs in the II phase of IMC. Due to the fact that after the phase III of IMC the contents of duodenogastric reflux is evacuated from the stomach we can say that III phase acts as a gastric clearance.

In our study we found that all cases of gallbladder cholesterolosis have high values of E.R meaning hyperkinesia. We also noticed that cholesterolosis is associated with enhanced duodenal motility. These facts allow us to suppose that the gallbladder bile which contains a large amount of cholesterol and which is evacuated quickly in the duodenum can induce an enhanced duodenal motility. The duodegastric reflux requires two conditions: the open pylorus and the retrograde duodenal motor wave. We think that enhanced duodenal motility can fulfill these two conditions. The gallbladder cholesterolosis can be one of the etiological factors which produce duodenogastric reflux. All cases with duodenogastric reflux have high GERDQ score that means the duodenogastric reflux can aggravate gastroesophageal reflux. The fact that from 20 cases with duodenogastric reflux 10 cases have also esophagitis is an argument proving again the effect of duodenogastric reflux on gastroesophageal reflux.

\section{Conclusions}

1. In our study made on $59 \mathrm{c}$ which gastroesophageal reflux the duodenogastric reflux which operates bile into the stomach is frequent $34 \%$ of cases.

2. The association of duodenogastric reflux with gallbladder cholesterolosis can induce the supposition that duodenal bile rich in cholesterol can be the trigger for enhanced duodenal motility and duodenogastric reflux.

3. The duodenogastric reflux can aggravate gastroesophageal reflux.

\section{References}

1. Brillantino A, Monaco L, Schettino M, Torelli F, Izzo G, et al. (2008) Prevalence of pathological duodenogastric reflux and the relationship between duodenogastric and duodenogastroesophageal reflux in chronic gastroesophageal reflux disease. Eur $J$ Gastroenterol Hepatol 20: 1136-1143. 
2. Keane FB, Dimagno EP, Malagelada JR (1981) Duodenogastric reflux in humans: its relationship to fasting antroduodenal motility and gastric, pancreatic, and biliary secretion. Gastroenterology 81: 726-731. [Crossref]

3. Sporea I, Gluhovschi G (1999) Ghidpractic de ecografieabdominala Timisoara.Editura Helicon.

4. Mocanu M, Diculescu M, NicolaeT (2013) Evaluarea particularitatilor bolii de reflux la pacientiicu hernie gastrica transhiatala si steatoza hepatica din perspectiva eficientizarii acesteiasocieri Teza doctorat UMF Bucuresti.

5. Halling K (2007) Development of an enhanced questionnaire for the diagnosis of gastroesofageal reflux disease based on the Reflux Disease Questionnaire, the GERD Impact Scale and the Gastrointestinal Symptom Rating Scale Gut 56: A209.

6. King A, Macdonald C, OrnC (2007) Understanding gastroesophageal reflux disease (GERD ): a patient segmentation analysis. Scand J Gastroenterol 42: 21.

Copyright: $(\mathbb{O} 2015$ Mocanu MA. This is an open-access article distributed under the terms of the Creative Commons Attribution License, which permits unrestricted use, distribution, and reproduction in any medium, provided the original author and source are credited. 